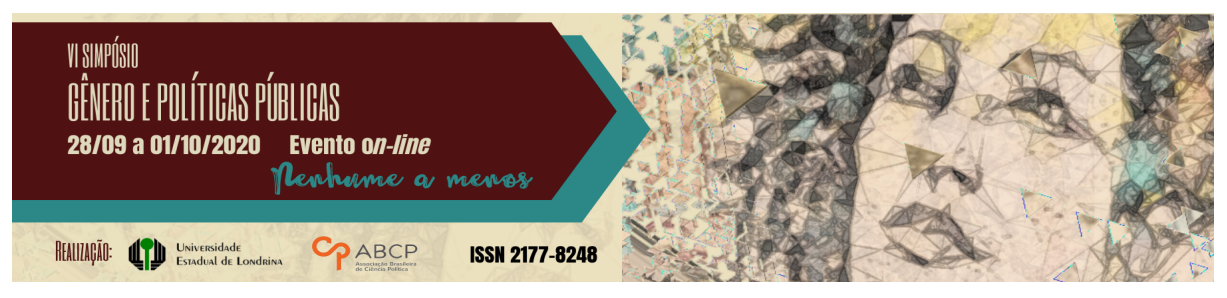

\title{
"O sexo do trabalho": reflexões sobre experiências laborais de trabalhadores/as transexuais e travestis
}

\author{
Carolina Gonçalves Santos de Brito ${ }^{1}$; Carla Cristina Lima de Almeida²
}

\begin{abstract}
Resumo
Trata-se de uma reflexão acerca das experiências laborais de trabalhadores/as transexuais e travestis, cuja direção analítica debruça-se a pensar, especialmente, de que modo este segmento é incorporado na divisão sexual do trabalho. Hierarquia, subordinação e desigualdade de gênero (re) produzidas no interior das relações e práticas de trabalho conformam condições ainda mais precárias de inserção e permanência de pessoas trans no mundo do trabalho. Nesta esteira, problematiza-se as políticas públicas de trabalho, emprego e renda em torno do recorte da diversidade de gênero, bem como o direito à saúde, ao nome social e à retificação do registro civil de modo interseccionado ao direito ao trabalho de pessoas trans.
\end{abstract}

Palavras-chave: diversidade de gênero; divisão sexual do trabalho; políticas públicas.

\section{"The sex of work": reflections on labor experiences of transsexuals and travesties workers}

\begin{abstract}
It is a reflection on the work experiences of transsexual and transvestite workers, whose analytical direction focuses on thinking, especially, how this segment is incorporated into the sexual division of labor. Hierarchy, subordination and gender inequality (re) produced within relations and work practices conform even more precarious conditions for the insertion and
\end{abstract}

\footnotetext{
1 Doutoranda pelo Programa de Pós-graduação em Serviço Social da UERJ, carolina.gsb@hotmail.com.

2 Faculdade de Serviço Social da UERJ, Doutora em Ciências Sociais, carlacristina.almeida@yahoo.com.br.
}

GT 14 - Gênero, trabalho e sindicalismo 
permanence of trans people in the world of work. In this context, public labor, employment and income policies are problematized around the cut of gender diversity, as well as the right to health, the social name and rectification of the civil registry in an intersection with the right to work of trans people.

Keywords: gender diversity; sexual division of labor; public policy.

\section{Introdução}

A pandemia da COVID-19, em meio ao aprofundamento da agenda ultraneoliberal, reacionária, neofascista, aliada à "ofensiva antigênero" (PRADO; CORREA, 2018), expõe de maneiras diversas as profundas desigualdades de classe, gênero, sexualidade e raça, que conformam nossa formação sócio-histórica. A pandemia atinge sobremaneira o conjunto da classe trabalhadora, e, mais especialmente, camadas mais vulneráveis, como mulheres, negros/as, pessoas LGBTI e, neste segmento, particularmente pessoas trans ${ }^{3}$.

A distribuição desigual dos efeitos da pandemia sentidos pela população trans explicitam sua condição de grupo historicamente discriminado, marginalizado e exposto a condições ainda mais precárias de acesso a direitos, dentre os quais, o direito ao trabalho.

Pessoas com pertencimento de gênero dissidente do assignado no nascimento experienciam condições e relações de gênero e, indissociavelmente, de trabalho, assimétricas e desiguais. Esses são processos que impulsionam a pensar acerca do lugar que trabalhadores/as transexuais e travestis ocupam na divisão sexual do trabalho e do mercado de trabalho, bem como acerca de legislações e/ou políticas públicas afetas ao direito ao trabalho de pessoas trans.

\footnotetext{
${ }^{3}$ Falamos em pessoas trans para nos referir às pessoas travestis, transexuais (homens trans e mulheres trans), não-binárias e demais pessoas que, em qualquer momento da vida, desenvolvem identidades dissidentes ao gênero imposto quando do nascimento, atribuído com base na anatomia genital.
} 


\section{Trajetórias laborais trans à luz da problemática da divisão sexual do trabalho}

A divisão sexual do trabalho não é uma problemática nova no âmbito das ciências sociais. Estudos feministas em torno desta problemática há tempo (a exemplo, Kergoat, 1989; Souza-Lobo, 1991; Hirata; Kergoat, 1994; Hirata, 2002) questionam e recusam categorias e paradigmas sexualmente cegos predominantes nas ciências sociais e nas pesquisas e análises que tratam da classe trabalhadora e do mundo do trabalho (SOUZA-LOBO, 1991; HIRATA; KERGOAT, 1994).

Ao chamar a atenção para as hierarquias e desigualdades de gênero existentes no interior das relações de produção, a literatura feminista acerca da divisão sexual do trabalho redefine quem é a classe trabalhadora, no sentido de "desomogeneizá-la" a partir da mediação entre as categorias gênero e classe.

Esta literatura reivindica, portanto, a imprescindibilidade de pensar a classe trabalhadora no feminino, o que consiste numa tarefa difícil, nas palavras de Souza-Lobo (et. al, 1986, p. 131), "porque considerada como um desvio em relação aos assuntos importantes". Esta dificuldade guarda relação com dinâmicas de resistência institucional presentes nas ciências sociais "que, ao fixar fronteiras entre teorias gerais e particulares, termina por compartimentar problemáticas que atravessam as relações sociais e, ao serem circunscritas a espaços 'específicos', são isoladas e perdem todo alcance e extensão" (SOUZALOBO, 1991, p. 149).

A divisão sexual do trabalho "trata-se de uma problemática (e não da abertura de um novo campo regional) que atravessa e dá sentido ao conjunto das relações sociais que a expressão 'divisão social do trabalho' abrange" (KERGOAT, 2002, p. 235). Neste sentido, ainda de acordo com Kergoat (1989, p. 89), a divisão sexual interpenetra-se com outras formas de divisão social do trabalho, a exemplo da divisão entre o trabalho manual e o trabalho intelectual, da divisão internacional do 
trabalho (KERGOAT, 1989, p. 89) e da divisão racial do trabalho (GONZÁLEZ, 2018).

O aporte teórico-metodológico de pesquisas sobre a divisão sexual do trabalho produz avanços na teoria crítica ao romper com perspectivas analíticas que levam em conta apenas as relações e práticas de classe enquanto estruturais e constitutivas das relações e práticas de trabalho e relações e práticas sociais. Nas palavras de Souza-Lobo (1991, p. 146, grifos nossos), a ideia de que a divisão sexual do trabalho não somente separa e articula produção e reprodução, mas estrutura as relações no âmbito do trabalho produtivo, "permite recolocar a questão da relação entre a dinâmica das relações capitalistas de trabalho e a força de trabalho feminina sob um ângulo que integra os dois níveis, sexualizando as relações de trabalho e as relações sociais".

Pesquisas feministas em torno da divisão sexual do trabalho notabilizam, portanto, que a possibilidade de compreender as desigualdades (re) produzidas e apropriadas no ordenamento do trabalho na sociedade capitalista está intimamente vinculada ao questionamento das relações e práticas de trabalho supostamente assexuadas ou "neutras", paradigmas "gender-blinded" ainda predominantes no âmbito da sociologia do trabalho, visto que não consideram os resultados das pesquisas sobre divisão sexual do trabalho e relações de sexo/gênero, como constata Hirata (2006, p. 200).

Ao tempo que pesquisas e análises voltadas à problemática da divisão sexual do trabalho ainda carecem, em grande medida, de visualizar e incorporar o debate em torno das dissidências de gênero. Trabalhadoras/es travestis e transexuais experienciam de forma ainda mais agudizada as desigualdades sociais (re) produzidas no entrecruzamento de classe, gênero e raça, donde no momento contemporâneo de acirramento da precarização das condições e relações de trabalho, experiências laborais trans se situam ainda mais suscetíveis a condições desfavoráveis, precárias e degradantes. Neste 
sentido, pensar o "sexo do trabalho" 4 de modo sensível às questões trans permite, a nosso ver, análises refinadas acerca das dinâmicas de exploração, dominação e opressão a que está submetida a classe trabalhadora.

A inserção e a permanência de pessoas trans no mercado de trabalho compõem-se de inúmeras dificuldades, especialmente quando no início de modificações corporais e/ou ainda não lograda a retificação de nome e sexo no registro civil. No processo seletivo, trabalhadoras/es trans não raras vezes são selecionadas/os ao preenchimento da vaga, mas são preteridas/os no momento da contratação em razão da suposta discordância entre corporalidade/identidade de gênero e a documentação apresentada.

À permanência no local de trabalho, outras dificuldades são impostas, a exemplo da disponibilidade de banheiros e uniformes em conformidade com a identidade de gênero expressa pelo/a próprio/a trabalhador/a; do desrespeito ao nome social no que diz respeito ao tratamento, à identificação em crachás etc.; da solicitação de mudança da aparência ou do comportamento no ambiente de trabalho; de "piadas/chacotas", perseguições e diversas outras formas de preconceito e/ou discriminação.

Ademais, em algumas trajetórias laborais, a afirmação da identidade trans e/ou início de modificações corporais podem ser acompanhadas pela perda do vínculo empregatício, e o/a trabalhador/a pode priorizar a reunião de condições objetivas e subjetivas antes de fazê-las, mediante a inserção noutros locais de trabalho ou processos de diálogo e negociação no atual.

A violação da intimidade e privacidade do/a trabalhador/a trans no seio das relações interpessoais e institucionais nos ambientes

\footnotetext{
4 O livro $O$ sexo do trabalho publicado originalmente no ano de 1984 na França reúne contribuições feministas que põem em evidência a classe trabalhadora no feminino, a divisão sexual do trabalho, o vínculo orgânico entre relações e práticas de trabalho e relações e práticas de gênero e a indissociabilidade entre relações de classe e de sexo/gênero.
} 
laborativos em que se inserem, pela constante inspeção, vigilância e controle de corpos dissidentes que não "parecem apropriadamente generificados", nos termos de Butler (2000, p. 157), também conforma a sistemática violação de direitos e o amálgama bastante diversificado de dificuldades que acompanham experiências laborais trans.

Oliveira (2019) observa o "messianismo patronal" presente nas experiências laborativas de trabalhadoras mulheres trans e travestis, pois na relação empregada-empregador/a, o/a último/a tende a se imbuir de atributo messiânico pela contratação de funcionárias trans, e, assim, a assumir posturas mais exigentes em relação às mesmas.

A instabilidade de trabalho e, com efeito, o maior engajamento no emprego rondam a trajetória ocupacional da classe trabalhadora na sua totalidade. Antunes e Praun (2015, p. 417) evidenciam que no mundo do trabalho presencia-se "um projeto que transita entre as incertezas do mercado e a necessidade do engajamento como saída para se manter empregado". Ao considerarmos que o processo de radicalização da precarização social no mundo do trabalho também comporta uma divisão sexual, podemos pensar a possível agudização deste engajamento como saída para manter-se empregado/a no segmento de trabalhadores/as trans.

Experiências laborais trans evidenciam que concepções hegemônicas de feminilidade e masculinidade - cuja referência reside na ordem de gênero cisheteronormativa, patriarcal e também racista são, necessariamente, (re) produzidas nas relações e práticas de trabalho. Com efeito, trabalhadores/as transexuais e travestis, com frequência, estão submetidos/as a processos de negociações da própria condição sexo/gênero no âmbito da divisão sexual do mercado de trabalho.

Se levamos em conta que as relações e práticas de trabalho são sexualizadas, podemos refletir que a absorção diferenciada e desigual do segmento trans na divisão sexual do trabalho e do mercado de trabalho é, em grande proporção, mediada, entre outros aspectos, pela 
construção corporal no gênero afirmado, pelas performances de masculinidades/feminilidades corporificadas, bem como pelo reconhecimento jurídico da identidade de gênero, que, interseccionados, podem ensejar às pessoas trans condições mais ou menos favoráveis de acesso ao trabalho remunerado, visto que esse acesso se dá de forma indissociável dos marcadores e das relações sociais de gênero, sexualidade e raça.

Biroli (2018, p. 47) problematiza que "a divisão sexual do trabalhoé produtora do gênero, ainda que não o seja isoladamente. Ela compõe as dinâmicas que dão forma à dualidade feminino-masculino". Nestes termos, argumentamos que experiências laborais trans trazem problemáticas que põem em evidência a complexidade e outras dimensões da dinâmica da divisão sexual do trabalho, à medida que possíveis de serem visualizadas a partir das transições de gênero, e das violações de direitos que com frequência as acompanham no mundo do trabalho e fora dele.

O trabalho na expressão trans ilumina notadamente os efeitos da concepção cisheteronormativa no ordenamento do trabalho, explicitado notoriamente, de acordo com Rodrigues e Nardi (2008), no lugar abjeto que performances não cisnormativas e não heteronormativas ocupam no mercado de trabalho.

Diante das agudizadas dificuldades de ingresso e/ou permanência no trabalho regulamentado e contratado, muitas pessoas travestis e transexuais são impelidas a "se virar" no mundo laboral para viabilização do sustento diário, donde estratégias ocupacionais variadas acionadas na informalidade do mercado de trabalho de modo a auferir alguma remuneração. Trata-se, com frequência, de ocupações precárias, muitas como alternativas mais imediatas ao desemprego completo constituindo-se como única estratégia de sobrevivência, caracterizadas, em geral, pela incerteza de trabalho, pela remuneração mais instável e/ ou precária e pelo desabrigo de direitos sociais do trabalho. 
Este modo precário de sobrevivência pode ser agudizado nas trajetórias de vida de pessoas trans que, na ausência e/ou instabilidade de trabalho e de renda, não dispõem de proteção social da família de origem, face à, não rara, fragilização/rompimento de vínculos familiares devido a não aceitação de sua identidade/expressão de gênero, donde a satisfação de suas necessidades básicas de reprodução social pode depender mais expressivamente da fonte de renda do seu trabalho.

Importa salientar o caráter inerentemente contraditório da família:

Afinal, a família como toda e qualquer instituição social, deve ser encarada como uma unidade simultaneamente forte e fraca. Forte porque ela é de fato um locus privilegiado de solidariedades, no qual os indivíduos podem encontrar refúgio contra o desamparo e a insegurança da existência. Forte, ainda, porque nela que se dá, de regra, a reprodução humana, a socialização das crianças e a transmissão de pensamentos que perduram pela vida inteira das pessoas. Mas ela também é frágil, pelo fato de não estar livre de despotismos, violências, confinamentos, desencontros e rupturas. Tais rupturas, por sua vez, podem gerar insegurança, mas também podem abrir portas para a emancipação e bem-estar de indivíduos historicamente oprimidos no seio da família, como mulheres, crianças, jovens, idosos (PEREIRA-PEREIRA, 2010, p. 36-7).

A ausência/fragilidade de mecanismos de ajuda mútua, de solidariedade e de suporte afetivo e econômico frequentemente geridos na rede social familiar de origem pode situar pessoas travestis e transexuais em condições mais desfavoráveis de minimizar os riscos sociais que a condição de trabalhador/a trans as/os situa na divisão sexual do trabalho. Ao tempo que trajetórias laborais trans conformadas expressivamente pelo acesso desigual ao mundo do trabalho podem submeter também familiares que dependem para a garantia do seu sustento, em alguma medida, da renda do/a trabalhador/a trans a 
constâncias de riscos e precariedades de condições de reprodução social.

A inserção ora desprotegida e precária no mercado de trabalho, ora no desemprego direto, expressiva nas experiências laborais trans, conforma precariedades e incertezas no mundo do trabalho e no mundo do consumo, com implicações deletérias ao atendimento das necessidades sociais na sua totalidade, o que também abrange as necessidades/urgências relacionadas ao processo de afirmação de gênero, a exemplo do acesso a modificações corporais demandadas (procedimentos cirúrgicos, medicamentos hormonais, por exemplo), às quais competem dispor de recursos econômicos, especialmente diante de insuficientes serviços disponíveis relacionados ao processo transexualizador no âmbito do Sistema Único de Saúde (SUS).

Neste sentido, como Almeida (2018, p. 180) evidencia:

As trajetórias no trabalho remunerado compõem um mapa complexo no qual se entrecruzam, entre outros aspectos: o acesso que trans terão (ou não) às tecnologias e recursos capazes de contribuir para a transformação dos seus corpos (em conformidade com suas necessidades/desejos); a segurança e proteção social da qual irão dispor para tomarem decisões relativas aos seus processos identitários; a forma como elaboram subjetivamente as experiências e constroem alternativas para lidar com as intercorrências das transformações corporais, subjetivas e sociais, já que tais sujeitos têm urgência e essa não pode ser desconsiderada.

O processo de afirmação de gênero consiste num conjunto de alterações corporais e sociais (BENTO, 2008), e, com efeito, cabe à política de saúde, educação, trabalho, previdência social, assistência social, entre outras, além do Poder Judiciário, uma ampla e complexa teia de ações, o que significa a imprescindibilidade da intersetorialidade, pois entendida como esforço coletivo no campo das políticas públicas com vistas à superação das dicotomias e intervenções isoladas (ALMEIDA; SANTOS, 2014, p. 204). 
O direito ao trabalho de pessoas trans envolve outros direitos e políticas, como o direito à retificação de nome e sexo no registro civil, o direito ao nome social, o direito a modificações corporais, conforme necessidade/desejo da pessoa trans, para além, notoriamente, de políticas públicas de trabalho, emprego e renda em torno do recorte da diversidade de gênero.

\section{Direito ao trabalho de pessoas trans: notas sobre o caminho da institucionalidade}

No âmbito das políticas públicas de trabalho, assistência social e previdência social, Mello (et. al, 2013, p. 137) destacam que há uma explícita escassez de referências normativas no que tange aos direitos da população LGBT, porém, inúmeros documentos do Governo Federal, voltados ao combate à homofobia e à promoção da cidadania de pessoas LGBT, apresentam ações e propostas relativas às referidas políticas, a exemplo do Programa Brasil sem Homofobia (BSH/2004), do Plano Nacional de Promoção da Cidadania e Direitos Humanos LGBT (2009) e do Programa Nacional de Direitos Humanos 3 (PNDH-3/2009).

Deve ser destacado, porém, que entre a formulação e a implementação de políticas públicas para a população LGBT, o caminho geralmente é longo, tortuoso e cheio de percalços, antes de tudo em face das fortes resistências morais, prevalecentes no interior de muitos órgãos governamentais, no que diz respeito à garantia da cidadania das pessoas que não correspondem aos estereótipos sexuais e de gênero (MELLO et al, 2013, p. 137).

A despeito do número expressivo de documentos governamentais, "o que se tem é um enorme silêncio em relação às ações do Governo Federal nas áreas de assistência social, previdência social e trabalho", voltadas à população LGBT (MELLO et al, 2013, p. 145), constituindo iniciativas mais no "campo da intenção" do que no "campo da ação" (MELLO et al, 2013, p. 147). Nas esferas federal, estaduais e municipais no âmbito da política de trabalho configuram-se ações, 
programas e projetos esparsos, fragmentados, frágeis, de cobertura limitada, além de instáveis pois a depender de conjunturas governamentais (MELLO et al, 2013).

Nesta esteira de iniciativas (esparsas e frágeis) de trabalho e renda pelo poder público, podemos registrar o Projeto Trans+Respeito da Prefeitura do Rio $^{5}$ voltado à inserção de travestis, mulheres trans e homens trans no mercado de trabalho. Na pesquisa de uma das autoras (BRITO, 2019) a respeito de trajetórias laborais de homens trans, Antônio (nome fictício), um de nossos interlocutores, de 35 anos e pardo, conforme sua autoidentificação, trabalhava (no momento da pesquisa) como recepcionista de um Museu localizado no município do Rio de Janeiro, sob vínculo empregatício formal. A inserção neste emprego se deu através de um processo seletivo destinado à contratação de pessoas trans, pois o Museu apoiou e aderiu o referido Projeto Trans+Respeito.

Antônio, que possuía ensino médio completo, bem como curso técnico de hotelaria/turismo realizado num Hotel, iniciou o processo de transição de gênero aproximadamente aos 30 anos. As experiências laborais na condição de trabalhador homem trans circunscreveram-se por distintos modos de inserção no trabalho informal, como assalariamento sem registro, contratos temporários e inserções laborativas ocasionais, bem como pelo desemprego frequente. Assim, Antônio, trabalhando há "um ano e meio, quase dois anos" (SIC) na ocupação de recepcionista no Museu, nos relatou que "depois da transição praticamente esse aqui é o meu primeiro emprego fixo".

É valido registrar que antes do ingresso dos/as trabalhadores/as trans a gestão do Museu realizou ações de caráter

5 O Projeto Trans+Respeito é desenvolvido pela Secretaria Municipal de Assistência Social e Direitos Humanos (SMASDH) em conjunto com a Coordenadoria Especial da Diversidade Sexual (CEDSRIO). Trata-se do antigo Projeto Damas implementado pelos mesmos órgãos desde 2006, e, a partir de 2017, denominado Projeto Trans+Respeito. Informações disponíveis em: https://www.rio.rj.gov.br/web/cedsrio/exibeconteudo?id=6892301. Acesso em: ago. 2020. 
pedagógico direcionadas à equipe de funcionários/as, através de atividades informativas e educativas sobre a temática trans, bem como de sensibilização quanto ao respeito à identidade/expressão de gênero, com o objetivo de promover uma cultura organizacional nãodiscriminatória.

Tal iniciativa constitui de fundamental importância, e precisa ser considerada na seara de planos, programas e projetos em torno da política de trabalho e emprego voltada à população transexual e travesti, pois que, a dificuldade de pessoas trans de lograr o direito ao trabalho não se restringe à inserção no mercado de trabalho, à medida que situações de constrangimentos, humilhações e discriminações outras compõem, com frequência, o dia a dia laboral destes/as trabalhadores/as, cuja uma das resultantes consiste em migrações constantes de trabalho e interrupções de projetos de carreira profissional em busca de ambientes laborais menos hostis e degradantes.

No campo das políticas públicas LGBTI, caracterizadas, em geral, pela fragilidade, em razão de não possuírem orçamento próprio e regulamentação jurídico-legal, muitas vezes criadas a partir de portarias, as políticas de trabalho, emprego e renda permanecem sem qualquer avanço no que diz respeito à transversalidade de gênero e orientação sexual (IRINEU et al, 2019, p. 267).

Diante deste cenário de fragilidades no campo das políticas públicas LGBTI, constitui indispensável registrar iniciativas na agenda do ativismo trans preocupadas com questões afetas ao trabalho e à renda para este segmento, a exemplo do projeto TransEmpregos. Este projeto consiste numa página criada no ano de 2013 pelo ativismo trans, com o objetivo de mediar a inserção de pessoas travestis e transexuais no mercado de trabalho formal. Assim, dentre outras ações, possui banco de dados para cadastramento de currículos, divulga em plataformas da internet vagas ofertadas para este segmento e realiza sensibilização e capacitação junto às empresas. Cabe ainda pontuar que 
o projeto TransEmpregos conta, até o presente momento, com 500 empresas parceiras ${ }^{6}$.

No que tange à política estatal brasileira de saúde, a instituição do processo transexualizador no âmbito do SUS constitui um avanço no reconhecimento do direito da população trans ao acesso à saúde, no entanto, a realidade atual dos serviços disponíveis configura-se longe de assegurar efetivamente as demandas desta população, visto que restringe numericamente a população usuária atendida, além de não abarcar todas as demandas daqueles/as que conseguiram se inserir na rede ${ }^{7}$.

Procedimentos cirúrgicos/biomédicos embora previstos formalmente, mediante normativas do Ministério da Saúde, colidem com limitações concretas nas Unidades do SUS, a exemplo da escassez de recursos orçamentários, técnicos e humanos, dentre outras dificuldades, como o preconceito e/ou discriminação por parte de alguns/mas profissionais, impondo óbices ao acesso de pessoas trans a serviços de saúde.

Ademais, Almeida (2018, p. 172) aponta que o Estado pouco tem demandado o mercado privado da saúde a também assumir procedimentos relacionados ao processo transexualizador de seus usuários/clientes. A realidade da maioria dos programas públicos é,

6 Informações disponíveis em: https:/ / www.transempregos.org/. Acesso em agosto de 2020. A natureza dos postos de trabalho/nichos ocupacionais que tem sido direcionada à contratação de pessoas trans, através da dinâmica de oferta de vagas veiculadas em plataformas da internet, está por ser aprofundada em trabalhos futuros.

7 Em 2008, o Ministério da Saúde (MS) aprova a primeira Portaria ( $\left.n^{\circ} 1.707\right)$ que institui o processo transexualizador no âmbito do SUS. No mesmo ano, esta Portaria é revogada pela Portaria $n^{\circ} 457$. Esta última contempla mulheres trans como usuárias do serviço. No ano de 2013, o MS redefine e amplia o processo transexualizador no SUS a partir da Portaria $\mathrm{n}^{\mathrm{o}} 2.803$, a qual expande o acesso para travestis e homens trans. No SUS, dez estabelecimentos são habilitados como Unidade de Atenção Especializada no Processo Transexualizador, sendo cinco centros hospitalares e ambulatoriais e cinco centros com atenção apenas ambulatorial. Informações disponíveis em: http:/ / www.saude.gov.br/atencao-especializada-ehospitalar/especialidades/processo-transexualizador-no-sus/acesso-e-regulacao e https://www.saude.gov.br/noticias/agencia-saude/43482-hospital-no-es-faraatendimento-a-transexuais. Acesso em agosto de 2020. 
portanto, de filas intermináveis para realização de procedimentos, o que culmina na espera de muitos anos até a realização de todas as transformações corporais necessárias. Com efeito:

As repercussões sociais da espera pelos procedimentos são evidentes: prolonga-se desnecessariamente um estado de insatisfação, forçase os indivíduos à "opção" pelo mercado privado e, por vezes, ilegal, e, em muitos casos, prolonga-se e promove-se a ausência de cidadania em seus termos mais elementares (direitos civis, direito de propriedade, direito ao trabalho) (ALMEIDA, 2018, p. 172).

No que diz respeito ao direito à alteração da documentação civil, a decisão do Supremo Tribunal Federal (STF) sobre a Ação Direta de Inconstitucionalidade n. ${ }^{\circ} 4275$, em março de 2018, dispensa a necessidade de judicialização do processo de retificação de nome e sexo no registro civil, que passa a então ser realizado por via administrativa nos cartórios de Registro Civil, independente de procedimentos hormonal ou cirúrgico, de testemunhas, bem como de laudos médicos e psicológicos.

Esta decisão significa, pois, a luta histórica do movimento travesti e transexual, representando uma inegável conquista, pois como Ventura (2010, p. 152) aponta, o não reconhecimento do direito de pessoas trans à alteração do nome e sexo no registro civil lesiona preceitos fundamentais da Constituição Federal, entre os quais, o princípio da dignidade da pessoa humana, da vedação à discriminação, da igualdade, da liberdade e da privacidade.

No entanto, apesar da decisão do STF e da regulamentação pelo Conselho Nacional de Justiça (CNJ) há denúncias de resistências e recusas por parte de alguns Cartórios à retificação da documentação, negando o atendimento, solicitando laudos médicos ou psicológicos ou encaminhando à judicialização, entre outras barreiras enfrentadas pelas pessoas trans. 
Tais violações no acesso ao direito à retificação de nome e sexo incidem em diversas dimensões da vida e direitos das pessoas trans, inclusive no que se refere ao direito à inserção/manutenção no mundo trabalho. $\mathrm{O}$ acesso à retificação da documentação civil, bem como a modificações corporais, especialmente interseccionadas, conforme necessidade/desejo da pessoa trans, pode contribuir favoravelmente nas condições e relações de trabalho sexualizadas e permitir maior conforto e segurança no que diz respeito ao reconhecimento/respeito da identidade/expressão de gênero nas interações cotidianas e rotineiras no ambiente laboral.

Por outro lado, é indispensável considerar que pessoas trans podem não desejar, ou não possuir condições econômicas e sociais de realizar, modificações corporais e/ou a retificação do registro civil. Isto guarda relação também com condições subjetivas e objetivas disponíveis nas particulares trajetórias de vida, a exemplo das relações familiares, do pertencimento geográfico, da inserção (ou não) no ambiente de trabalho...

Quando não lograda/desejada a alteração da documentação civil, o desrespeito ao nome social (e, portanto, à identidade/ expressão de gênero) do/a trabalhador/a trans compõe as múltiplas formas de subordinação e discriminação de gênero (re) produzidas nas relações e práticas de trabalho que, com efeito, conformam dificuldades e violações de direitos nas experiências laborativas trans desde o processo de seleção à permanência e promoção no posto de trabalho ${ }^{8}$.

\footnotetext{
8 Há normativas, especialmente mediante portarias, decretos e resoluções, orientadas ao respaldo do direito ao uso do nome social em alguns âmbitos. Vale mencionar, entre outros instrumentos, a Portaria $\mathrm{n}^{\mathrm{0}} 1.820 / 2009$, do Ministério da Saúde, a qual assegura o uso do nome social no âmbito do SUS, bem como o Decreto Presidencial no 8.727/2016, o qual dispõe sobre o uso do nome social no âmbito da administração pública federal direta, autárquica e fundacional. No entanto, mesmo em esfera provida de dispositivos legais, o direito ao uso do nome social muitas vezes não é garantido, além de existir disparidade de regulamentação entre estados e municípios, bem como entre setores público e privado. Neste sentido, há instabilidade no reconhecimento do direito ao nome social, pois condicionado a determinados âmbitos da vida social, a depender da existência e da implementação de regulamentações legais.
} 
Frequentemente, trabalhadoras/es travestis e transexuais elaboram negociações cotidianas e sofisticadas junto a empregadores/as, superiores hierárquicos/as, colegas de trabalho quanto ao reconhecimento do uso do nome social. Trata-se de negociações muitas vezes conflituosas e instáveis. Em algumas experiências laborais a pessoa trans pode, por exemplo, encontrar resistências por parte de alguns/mas colegas de trabalho. Em outras experiências, $\mathrm{o} / \mathrm{a}$ trabalhador/a trans pode obter o reconhecimento do direito ao uso do nome social, no entanto, a mudança, por exemplo, da equipe de chefia, gerência, funcionários/as e de protocolos institucionais, pode trazer a incerteza acerca da manutenção deste direito.

Tais negociações, ademais, tecidas pelas pessoas trans, no que diz respeito, por exemplo, ao uso do nome social, à disponibilidade de banheiros e uniformes condizentes à identidade/expressão de gênero, evidenciam problemáticas capazes também de produzir fissuras e alterações nas rotinas, relações e práticas de trabalho e de gênero nos ambientes laborais em que trabalhadores/as trans inserem-se.

No Brasil, até o presente momento, registra-se a inexistência de legislação aprovada no Congresso Nacional referente aos direitos da população LGBTI. Bento (2014) argumenta que na realidade brasileira há um modus operandi historicamente observável das elites que ocupam majoritariamente as esferas da representação política, qual seja: direitos a segmentos socialmente discriminados são garantidos a conta-gotas. A autora (BENTO, 2014) sugere, assim, que a cidadania precária compõe a cultura política brasileira e representa uma dupla negação:

Nega a condição humana e de cidadão/cidadã de sujeitos que carregam no corpo determinadas marcas. Essa dupla negação está historicamente assentada nos corpos das mulheres, dos/as negros/as, das lésbicas, dos gays e das pessoas trans (travestis, transexuais e transgêneros). Para adentrar a categoria de humano e de cidadão/cidadã, cada um desses corpos teve que se construir como "corpo 
político". No entanto, o reconhecimento político, econômico e social foi (e continua sendo) lento e descontínuo (BENTO, 2014, p. 167).

Prado e Correa (2018) evidenciam os efeitos deletérios das "cruzadas antigênero" em diversas partes do globo e, mais especialmente, no Brasil, em razão de sua penetração vertiginosa no aparato estatal. As "ofensivas antigênero" - as quais envolvem uma heterogeneidade de forças sociais, de cunho religioso e laico -, portanto, incidem em dimensões estruturais da vida política e social (PRADO, CORREA, 2018), convergindo na (re) produção e no acirramento de desigualdades.

O contexto contemporâneo de ultraneoliberalismo associado ao neofascismo, ao recrudescimento do conservadorismo e à "ofensiva antigênero", conforma uma agenda coadunada com o ataque aberto às instituições democráticas, às políticas sociais, aos direitos trabalhistas e previdenciários, aos direitos sexuais e de gênero, aos direitos à diversidade e à não discriminação.

Diante deste contexto, os processos de conquista/manutenção de direitos e políticas voltados à população LGBTI, bem como as condições de vida e de trabalho da classe trabalhadora na sua heterogeneidade, são direta e dramaticamente afetados. Coloca-se o desafio de intensificarmos nossas energias, respostas e lutas em torno do direito ao trabalho de pessoas transexuais e travestis, cuja condição de acesso e permanência é ainda mais precária e passível de violação.

\section{Considerações finais}

Souza-Lobo (1991, p. 125) evidencia que um dos argumentos presentes na resistência em trabalhar a problemática da classe como sexuada reside na ideia de associar a heterogeneidade da classe à fragmentação-divisão. Assim, "utiliza-se o espantalho da divisão da classe para reafirmar a determinação da estrutura produtiva de onde se deduz a classe como sujeito homogêneo". Nesta direção analítica, a 
autora (SOUZA-LOBO, 1991, p. 164) também nos alerta que pensar a classe trabalhadora no feminino exige o esforço de recusar a ideia de que o trabalho das mulheres consistiria numa "especificidade" na relação de trabalho "geral", isto é, o esforço "de evitar a armadilha da dicotomia entre análise de relações ditas gerais e de relações ditas 'específicas', como se existissem relações de trabalho neutras e relações de trabalho no feminino".

Nestes termos, pensar a classe como sexuada ou o "sexo do trabalho" a partir da problemática da diversidade de gênero problemática que ainda carece de preocupação e incorporação no âmbito da produção sociológica em torno da divisão sexual do trabalho - não se trata de "fragmentação-divisão" no interior da classe trabalhadora ou de "especificidade" a relações e práticas de trabalho supostamente "gerais", pelo contrário, fornece, a nosso ver, potencialidades para compreendermos a heterogeneidade de classe, gênero e raça bem como para desvelarmos e confrontarmos os processos de dominação-exploração de gênero, raça e classe no conjunto das relações sociais. Concordamos, com efeito, com a provocação de Arruzza et al (2019): um projeto societário verdadeiramente emancipatório nos exige respostas comprometidas com a luta feminista, antiLGBTIfóbica, antirracista e anticapitalista.

\section{Referências}

ALMEIDA, Guilherme. Identidade de gênero com ênfase nas pessoas trans: particularidades e acesso à saúde, trabalho e educação. In: NOGUEIRA, L; HILÁRIO, E; PAZ, T. T; MARRO, K. (Org.). Hasteemos a bandeira colorida: diversidade sexual e de gênero no Brasil. São Paulo: Expressão Popular, 2018.

ALMEIDA, Guilherme; SANTOS, Márcia Cristina Brasil. Intersetorialidade na efetivação do processo transexualizador do SUS: uma indispensável utopia. In: MONNERAT, G. L; ALMEIDA, N. L. T. de; SOUZA, R. G. de. (Org.). A intersetorialidade na agenda das politicas sociais. Campinas: Papel Social, 2014. 
ANTUNES, Ricardo; PRAUN, Luci. A sociedade dos adoecimentos no trabalho. Serviço Social e Sociedade, São Paulo, n. 123, p. 407-427, jul./set. 2015.

ARRUZA, Cinzia et al. Feminismo para os 99\%: Um manifesto. São Paulo: Boitempo, 2019.

BENTO, Berenice. O que é transexualidade. São Paulo: Brasiliense, 2008.

BENTO, Berenice. Nome social para pessoas trans: cidadania precária e gambiarra legal. Contemporânea - Revista de Sociologia da UFSCar, São Carlos, v. 4, n. 1, p. 165-182, jan./jun. 2014.

BIROLI, Flavia. Gênero e desigualdades: limites da democracia no Brasil. São Paulo: Boitempo, 2018.

BRITO, Carolina Gonçalves Santos de. Diversidade de gênero no trabalho: trajetórias de inserção e permanência de homens trans no mercado de trabalho. Dissertação (Mestrado em Serviço Social) - Universidade do Estado do Rio de Janeiro, Rio de Janeiro, 2019.

BUTLER, Judith. Corpos que pesam: sobre os limites discursivos do sexo. In: LOURO, Lopes Guacira (Org.). O corpo educado: pedagogias da sexualidade. Belo Horizonte: Autêntica, 2000.

GONZÁLEZ, Lélia. Racismo e sexismo na cultura brasileira. In: UCPA - União dos coletivos Pan-Africanistas (Org.). Lélia González: primavera para as rosas negras. Diáspora Africana: Editora Filhos da África, 2018.

HIRATA, Helena. Nova divisão sexual do trabalho? um olhar voltado para a empresa e a sociedade. São Paulo: Boitempo, 2002.

HIRATA, Helena. Entrevista: Helena Hirata. Trabalho, Educação e Saúde, Rio de Janeiro, v. 4, n. 1, p. 199-203, mar./ago. 2006.

HIRATA, Helena; KERGOAT, Danièle. A classe operária tem dois sexos. Estudos Feministas, Florianópolis, v. 2, n. 3, p. 93-100, 1994.

IRINEU, Bruna. et al. "O samba começou e fez convite ao tango para parceiro"? A arena LGBTI em tempos de ofensiva neoliberal e "cruzada antigênero" no Brasil e na Argentina. Humanidades $e$ Inovação, Palmas, v. 6, n. 7, p. 254-270, 2019. 
KERGOAT, Danièle. Da divisão do trabalho entre os sexos. Tempo Social, São Paulo, v. 1, n. 2, p. 73-103, 1989.

KERGOAT, Danièle. Problemática da divisão sexual relacionada à divisão social, e problemas das relações sociais. In: HIRATA, H. Nova divisão sexual do trabalho? Um olhar voltado para empresa e a sociedade. São Paulo: Boitempo, 2002.

MELLO, Luiz. et al. Políticas públicas de trabalho, assistência social e previdência social para a população LGBT no Brasil: Sobre desejos, realizações e impasses. Revista de Ciências Sociais, Fortaleza, v. 44, n. 1, p. 132-160, jan./jun. 2013.

PRADO, Marco Aurélio Maximo; CORREA, Sonia. Retratos transnacionais e nacionais das cruzadas antigênero. Revista Psicologia Política, v. 18, n. 43, São Paulo, p. 444-448, set./ dez. 2018.

OLIVEIRA, João Felipe Zini Cavalcante de. "E travesti trabalha?": divisão transexual do trabalho e messianismo patronal. Dissertação (Mestrado em Direito) - Universidade Federal de Minas Gerais, Belo Horizonte, 2019.

PEREIRA-PEREIRA, Potyara Amazoneida. Mudanças estruturais, política social e papel da família: crítica ao pluralismo de bem-estar. In: SALES, M. A; MATOS, M. C. de; LEAL, M. C. (Org.). Política Social, Família e juventude: uma questão de direitos. São Paulo: Cortez, 2010.

RODRIGUES, Manoela; NARDI, Henrique. Diversidade sexual e trabalho: reinvenções do dispositivo. Bagoas, Natal, v. 2, n. 03, p. 127143, jul./dez. 2008.

SOUZA-LOBO, Elisabeth. et al. A "prática invisível das operárias". In: KARTCHEVSKY-BULPORT, Andrée et al. O Sexo do Trabalho. Rio de Janeiro: Editora Paz e Terra, 1986.

SOUZA-LOBO, Elisabeth et al. A classe operária tem dois sexos: trabalho, dominação e resistência. São Paulo: Brasiliense, 1991.

VENTURA, Miriam. A transexualidade no tribunal: saúde e cidadania. Rio de Janeiro: EdUERJ, 2010. 